\title{
Evaluation of Pleural Fluid Adenosine Deaminase Activity in Tubercular Pleural Effusion in a Military Hospital
}

\author{
Uddin $M K^{1}$, Mia $A A^{2}$, Mostafi $M^{3}$, Parvin $M^{4}$, Chowdhury $M A^{5}$
}

\begin{abstract}
Introduction: Tubercular pleural effusion (TPE) is one of the common extra pulmonary tuberculosis which many a times become difficult to make definite diagnosis on account of low sensitivity and/or specificity of non-invasive diagnostic tools. Even pleural biopsy cannot establish all the diagnosis; rather after patient shows unwillingness to invasive procedure. A reliable sensitive and specific marker is required for early diagnosis of TPE as Bangladesh is a high Tuberculosis burden country. Adenine deaminase (ADA) may be a useful surrogate marker.
\end{abstract}

Objective: To find out a reliable sensitive and specific marker for early diagnosis of TPE as Bangladesh is a high Tuberculosis burden country.

Materials and Methods: This study carried out ADA estimations in 170 cases of pleural effusion at Combined Military Hospital (CMH) Dhaka. Efforts were made to reach diagnosis by other means.

Results: ADA level was found in tubercular pleural effusion ranges from 25 to 180 with a mean 71.51 \pm 33.1 . It ranges $3 \mathrm{U} / \mathrm{L}$ to $170 \mathrm{U} / \mathrm{L}$ with non-tubercular effusion with a mean $20.96 \pm 16.71$. The sensitivity of ADA is $90.9 \%$ and specificity is $95.7 \%$ in diagnosing TPE. The positive and negative predictive values are $90.91 \%$ and $95.65 \%$ respectively.

Conclusion: ADA is found cheap, sensitive and a useful surrogate marker. However, it is not a confirmatory diagnostic tool but can be used as a reliable adjunct to other investigations.

Key-words: Adenine deaminase (ADA), Tubercular pleural effusion (TPE), Malignant pleural effusion (MPE).

\section{Introduction}

Tuberculosis (TB) has existed for millennia and remains a major global health problem. It causes ill-health in millions of people each year and in 2015 was one of the top 10 causes of death worldwide, ranking above HIVIAIDS as one of the leading causes of death from an infectious disease ${ }^{1}$. Among the extra pulmonary tuberculosis tubercular pleural effusion is frequently encountered by physicians. Pleural tuberculosis is a common manifestation of extra pulmonary TB and with or without pulmonary TB is present in around $4 \%$ of all TB cases ${ }^{2}$. Histopathological and microbiological analysis of the pleural fluid or tissue may seem to be the most ideal method, but diagnosis cannot be reached in approximately $20 \%$ of the patients ${ }^{3}$. ADA is an enzyme catalyzing the conversion of the adenosine and deoxyadenosine to the inosine and deoxyinosine in the purine degradation pathway. Its quantity increases in the immature and non-differentiated $T$ lymphocytes following mitogenic and antigenic stimulation ${ }^{4}$.

\section{Materials and Methods}

Total 170 patients of either sex with pleural effusion who were admitted to Combined Military Hospital (CMH), Dhaka from January 2014 to November 2015 were studied. This study included these patients who were presented at Pulmonology department and also the patients who were referred to $\mathrm{CMH}$ Dhaka from other department as a diagnostic challenge. In all cases pleural effusions were aspirated and examined and were included in the study. Patients on antituberculosis treatment, pregnant, age under 12 years, non aspirable quantity of pleural fluid and previously been diagnosed to have malignant pleural effusion were excluded.

1. Lt Col Md. Kabir Uddin, MBBS, FCPS (Med), FCPS (Pulmonology), Assistant Professor of Medicine and Respiratory Medicine, CMH Dhaka 2. Maj Gen Md Abdul Ali Mia, MBBS, MCPS, FCPS(Med), Consultant Physician General, Bangladesh Armed Forces 3. Brig Gen Mamun Mostafi, MBBS, MACP(USA), FCPS, FRCP, Chief Physician, CMH Dhaka 4. Col Mimi Parvin, MBBS, FCPS(Path), Classified Spl in Pathology, AFIP 5. Maj Mainul Ahmed Chowdhury, MBBS, MD(Med), Classified Spl in Medicine, CMH Dhaka. 
Physical, biochemical, bacteriological and cytological study were carried out of effusion. Light's criteria was used to decide exudates and transudates and this required a blood sample to be collected on the day of thoracentesis to measure total protein and $\mathrm{LDH}$. All samples were tested for ADA value. ADA activity was determined by standard colorimetric method using adenosine deaminase assay kit (Diazyme ADS kit from Germany) by enzymatic kinetic method at Armed Forces Institute of Pathology (AFIP). ADA levels are calculated and expressed in unit per liter $(\mathrm{U} / \mathrm{L})$. The test took 90 minutes from blood collection. The specimen were kept in $2-8^{\circ} \mathrm{C}$ if the test was not possible in time.

Other test from pleural fluid such as RA, ANA were done in appropriate case. Mantoux test (MT), sputum for AFB and malignant cell, sputum for Gene X-pert, fiber optic bronchoscopy, FNAC transthoracic and FNAC lymph node, video assisted thoracic surgery (VATS), pleuroscopy and pleural biopsy were done depending on the probable underlying diseases to reach conclusive diagnosis. Pro BNP, Echo, thyroid hormone test, RA, ANA, anti CCP were used along with renal and liver function test in certain cases which demands to do so. Every effort was taken to reach diagnosis in difficult cases.

Tubercular pleural effusion (TPE) was diagnosed by histopathologically (presence of granuloma in biopsy specimen), microbiologically (presence of AFB in pleural fluid and/or sputum, MTB detected in Gene X-pert, Broncho alveolar lavage revealed AFB, exudative pleural effusion with no alternate explanation) and clinical features compatible with Tubercular pleural effusion and there was clear response to anti-TB drugs.

Malignant pleural effusions (MPE) were diagnosed by clinical features and presence of malignant cell in the pleural fluid/pleural biopsy, bronchial biopsy or BAL fluid, Transthoracic FNAC and Metastatic malignant cell in FNAC or biopsy of lymph node. Parapneumonic effusion and empyema were diagnosed with classical features as cough, sputum, highfever, and pleuritic chest pain, consistent pleural fluid analysis (culture and sensitivity and exclusion of any disease that can explain effusion while collection of pus in pleural space was diagnosed as empyema).
Other diagnosis such as congestive cardiac failure/ Left ventricular failure, chronic kidney disease, chronic liver disease with appropriate clinical findings of the particular disease and hypoalbuminaemia were present and other relevant investigation were consistent such as echo, Brain natriuretic peptide and ultrasonogram.

Undiagnosed was labeled when despite all investigations (Plural fluid analysis, CT scan of chest, biopsy Echo, thyroid hormone profile, connective tissue disease markers) being performed but failed to reach a diagnosis. The data processing and analysis was done by using the SPSS-21 version. Continuous variables were expressed as mean and standard deviations. Categorical variables were compared using the chi-square test. Some values were distributed in percentages by group.

\section{Results}

Out of 170 cases 107 (60.3\%) were males and 63 $(39.7 \%)$ were females (Table-I). The mean age was $45.96 \pm 17.89$ in tubercular cases and $54.16 \pm 13.44$ years in non-tubercular cases which is statistically significant ( $p$ value $<0.001$ )

Table-I: Comparison of age of the study subjects between two groups $(n=170)$

\begin{tabular}{|c|c|c|c|}
\hline $\begin{array}{l}\text { Age } \\
\text { (in years) }\end{array}$ & $\begin{array}{l}\text { Group-I (TB) } \\
(n=55)\end{array}$ & $\begin{array}{l}\text { Group-II (Non-TB) } \\
(n=115)\end{array}$ & $\begin{array}{c}p \\
\text { value }\end{array}$ \\
\hline$<20$ & $5(9.1 \%)$ & $1(0.9 \%)$ & \\
\hline $21-30$ & $6(10.9 \%)$ & $7(6.1 \%)$ & \\
\hline $31-40$ & $11(20.0 \%)$ & $13(11.3 \%)$ & \\
\hline $41-50$ & $9(16.4 \%)$ & $24(20.9 \%)$ & \\
\hline $51-60$ & $12(21.8 \%)$ & $40(34.8 \%)$ & \\
\hline $61-70$ & $8(14.5 \%)$ & $18(15.7 \%)$ & \\
\hline $71-80$ & $4(7.3 \%)$ & $12(10.4 \%)$ & \\
\hline Total & $55(100.0 \%)$ & $115(100.0 \%)$ & \\
\hline Mean $\pm S D$ & $45.96 \pm 17.89$ & $54.16 \pm 13.44$ & $0.001^{s}$ \\
\hline
\end{tabular}

Note: $\mathrm{S}=$ Difference is statistically significant

The most common complaints were cough $(76 \%)$, shortness of breath $(72 \%)$, and chest pain $(55 \%)$. Fever, loss of appetite, loss of body weight and night sweat were complained in $45 \%, 56 \%, 15 \%$ and $10 \%$ respectively. All patient had at least two or more complaints. Lymphadenopathy is found mostly in malignant pleural effusions (14 cases) and only 2 cases in TPE. 
Pleural fluid was transudative in 39 patients and was found to exudative in 131 patients. Chest X-ray revealed effusion mild to moderate in tubercular pleural effusion cases and mild to massive pleural effusion in malignant pleural effusion. Three patients required intercostals tube drainage due to massive effusion. Right sided effusion was more common in both TPE (37 cases $67.3 \%$ ) and MPE (66 cases $57.4 \%$ ); while bilateral pleural effusion (12 cases $10.4 \%$ ) is more in congestive cardiac failure and in chronic kidney diseases.

Mantoux test (MT) revealed positive in 55 cases. It was found positive in 30 of TPE and also found positive in 21 cases of MPE. The sensitivity and specificity was found $54.55 \%$ and $81.74 \%$ respectively and 10 $\mathrm{mm}$ or more were considered as positive and $<10$ $\mathrm{mm}$ as negative.

Adenine deaminase studies from pleural fluid were done in all patients in this study. The mean ADA value was found $37.31 \pm 33.21 \mathrm{U} / \mathrm{L}$. ADA level was found in tubercular pleural effusion ranges from 25 to 180 with a mean $71.51 \pm 33.1$. It ranged $3 \mathrm{U} / \mathrm{L}$ to $170 \mathrm{U} / \mathrm{L}$ with non-tubercular effusion with a mean $20.96 \pm 16.71$. In 55 patients, it was more than 40 $\mathrm{U} / \mathrm{L}$. Among the positive cases 40 cases were diagnosed as tubercular pleural effusion, 5 were diagnosed positive in non-tubercular effusions (2 cases in MPE in cases, 2 in empyema and one in Rheumatoid arthritis).

Table-II: ADA level in pleural fluid of study groups

\begin{tabular}{|l|l|l|c|}
\hline \multicolumn{1}{|c|}{ Table-II: ADA level in pleural fluid of study groups } \\
\hline $\begin{array}{l}\text { (n=55) } \\
\text { Mean } \pm \text { SD }\end{array}$ & $\begin{array}{l}\text { Group-II(Non-TB) } \\
(\mathbf{n}=\mathbf{1 1 5}) \\
\text { Mean } \pm \text { SD }\end{array}$ & $\begin{array}{c}\mathbf{P} \\
\text { value }\end{array}$ \\
\hline ADA & $\begin{array}{l}71.51 \pm 33.21 \\
(25-180)\end{array}$ & $\begin{array}{l}20.96 \pm 16.71 \\
(3-170)\end{array}$ & $<0.0001^{\mathrm{s}}$ \\
\hline
\end{tabular}

Note: $\mathrm{S}=$ Difference is statistically significant

The receiver operating characteristic curve (ROC) curve is shown in the figure-1. Through analysis of a ROC curve, the optimal cut off value was determined 40U/L. The area under the curve was 0.974 and the standard error was 0.011 (95\% Cl: 0.952-0.996). Basing upon this cut off value ADA sensitivity and specificity were 90.91 and $95.65 \%$ respectively. If the cut of value was taken $30 \mathrm{U} / \mathrm{L}$ then the sensitivity and specificity became 96.4 and 92.2 respectively. Again $50 \mathrm{U} / \mathrm{L}$ was considered the cut off value then the sensitivity and specificity become $67.3 \%$ and $96.5 \%$ respectively.

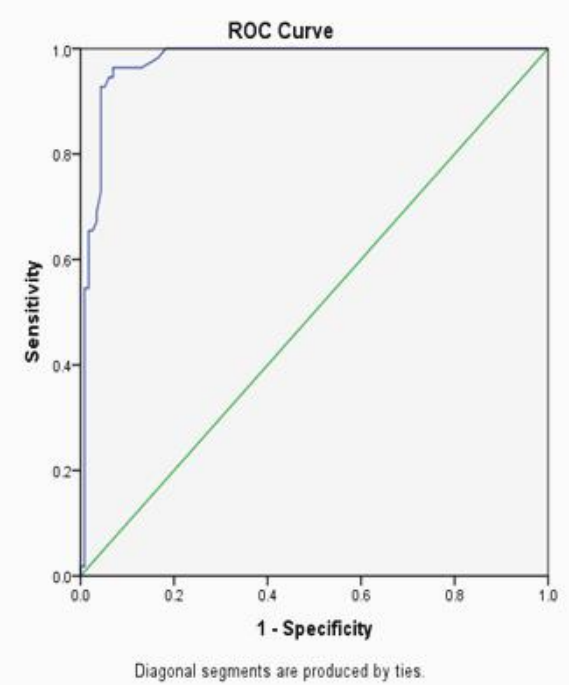

Fig-1: ROC curve from pleural effusion ADA values

Table-III: Area under the curve

\begin{tabular}{|l|c|c|c|c|}
\hline \multicolumn{4}{|l|}{ Area Under the Curve } \\
\hline \multicolumn{2}{|l|}{ Test Result Variable(s): } & \multicolumn{2}{l|}{ ADA in U/L } \\
\hline & & $P$ & $95 \%$ Confidence Interval \\
\cline { 4 - 5 } AUC & Std. Error & value & Lower Bound & Upper Bound \\
\hline 0.974 & 0.011 & 0.000 & 0.952 & 0.996 \\
\hline
\end{tabular}

The test result variable(s): ADA in U/L has at least one tie between the positive

Actual state group and the negative actual state group. Statistics may be biased.

a. Under the non-parametric assumption

b. Null hypothesis: true area $=0.5$

Sensitivity of ADA value was $90.91 \%$ and specificity was $95.65 \%$. The positive and negative predictive value was found $90.91 \%$ and $95.65 \%$ respectively.

Table-IV: Sensitivity and specificity of ADA for tubercular effusion

\begin{tabular}{|c|c|c|c|}
\hline ADA & TB & Non-TB & Total \\
\hline \multirow{2}{*}{ Positive } & (TP) & (FP) & 55 \\
& 50 & 5 & \\
\hline \multirow{2}{*}{ Negative } & (FN) & (TN) & 115 \\
& 5 & 110 & \\
\hline Total & 55 & 115 & 170 \\
\hline
\end{tabular}


Table-V: Determination of likelihood ratio, positive and negative predictive value

\begin{tabular}{|l|l|l|l|l|}
\hline & Value & $\mathbf{9 5 \%} \mathbf{C l}$ \\
\hline Sensitivity & $90.91 \%$ & $80.03 \%$ & to & $96.95 \%$ \\
\hline Specificity & $95.65 \%$ & $90.14 \%$ & to & $98.56 \%$ \\
\hline Positive Likelihood Ratio & 20.91 & 8.84 & to & 49.48 \\
\hline Negative Likelihood Ratio & 0.10 & 0.04 & to & 0.22 \\
\hline Disease prevalence & $32.35 \%$ & $25.39 \%$ & to & $39.94 \%$ \\
\hline Positive Predictive Value & $90.91 \%$ & $80.03 \%$ & to & $96.95 \%$ \\
\hline Negative Predictive Value & $95.65 \%$ & $90.14 \%$ & to & $98.56 \%$ \\
\hline
\end{tabular}

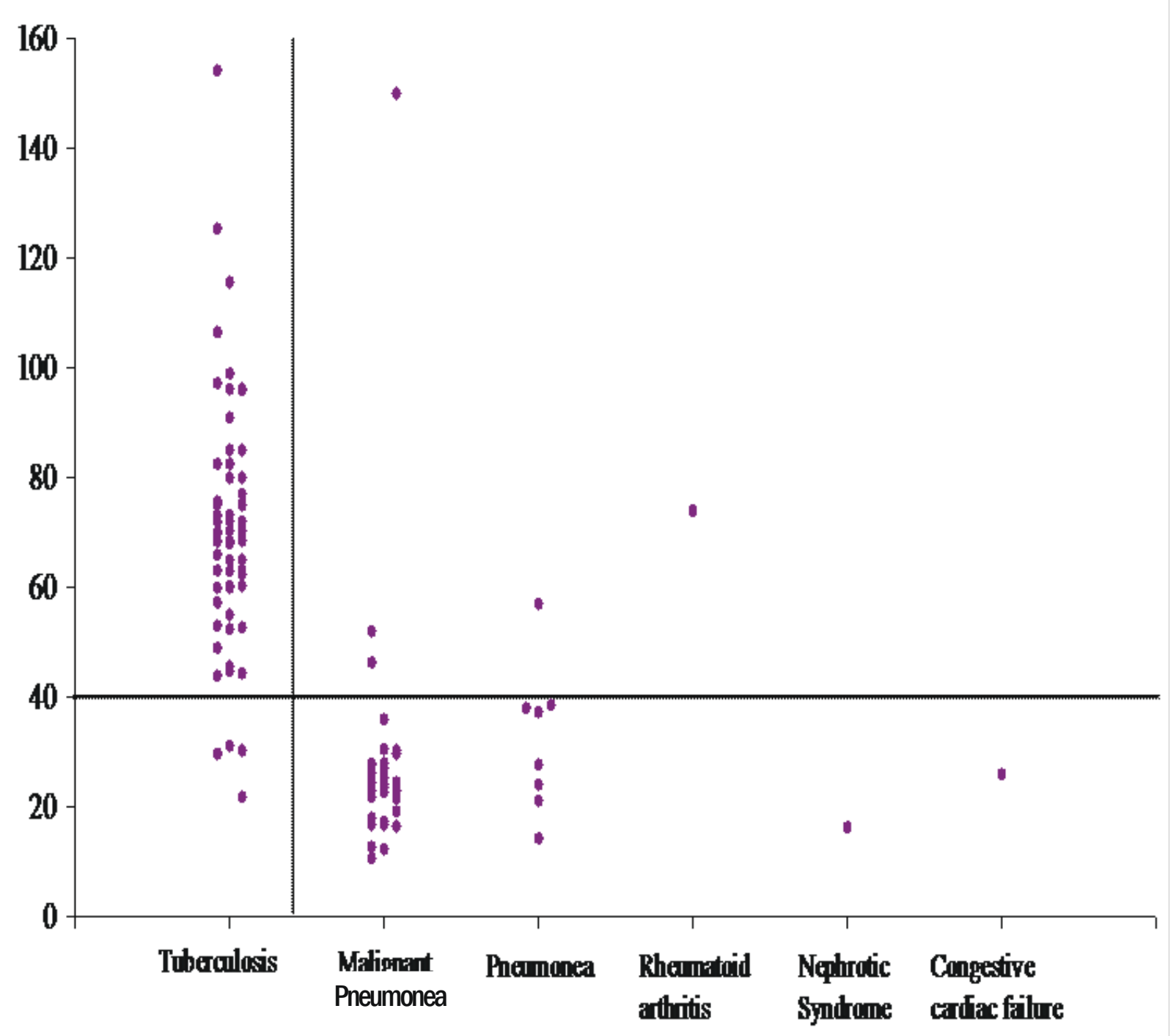

Fig-2: Adenosine deaminase levels in pleural fluids of the studied groups

Fiber optic bronchoscopy, transthoracic FNAC, FNAC from supra/cervical lymph node FNAC, video assisted thoracic surgery, pleuroscopy/pleural biopsy, pleural fluid cytology carried out 73, 50, 16, 11, 19 and 170 cases respectively. 
Table-VI: Invasive procedures* and their contributions to establishing diagnosis

\begin{tabular}{|l|l|l|l|l|l|l|}
\hline & $\begin{array}{l}\text { FOB } \\
\text { diagnostic/total* }\end{array}$ & $\begin{array}{l}\text { Pleural/pleuroscopy } \\
\text { biopsy diagnostic/total }\end{array}$ & $\begin{array}{l}\text { VATS } \\
\text { diagnostic/total }\end{array}$ & $\begin{array}{l}\text { Lymphnode biopsy } \\
\text { diagnostic/total }\end{array}$ & $\begin{array}{l}\text { CT guided FNAC } \\
\text { iagnostic/total }\end{array}$ & $\begin{array}{l}\text { Pleural fluid cytology, } \\
\text { bacteriological } \\
\text { examination* }\end{array}$ \\
\hline Tuberculosis & $5 / 23$ & $5 / 7$ & $5 / 5$ & $2 / 2$ & $3 / 8$ & $1 / 55$ \\
\hline Lung cancer/metastatic cancer & $12 / 41$ & $5 / 7$ & $4 / 5$ & $12 / 14$ & $17 / 38$ & $5 / 57$ \\
\hline Parapneumonic & $1 / 9$ & $1 / 3$ & - & - & 3 & $18 / 18$ \\
\hline Others & 9 & 2 & 1 & - & 1 & $5 / 16$ \\
\hline Total & $18 / 73$ & $11 / 19$ & $9 / 11$ & $14 / 16$ & $20 / 50$ & $29 / 170$ \\
\hline
\end{tabular}

FOB: fiber optic bronchoscopy LN: lymph nodeFNAC: fine needle aspiration cytology VATS: video assisted throacoscopic surgery * some cases underwent more than one invasive procedure and all patient had thoracentesis

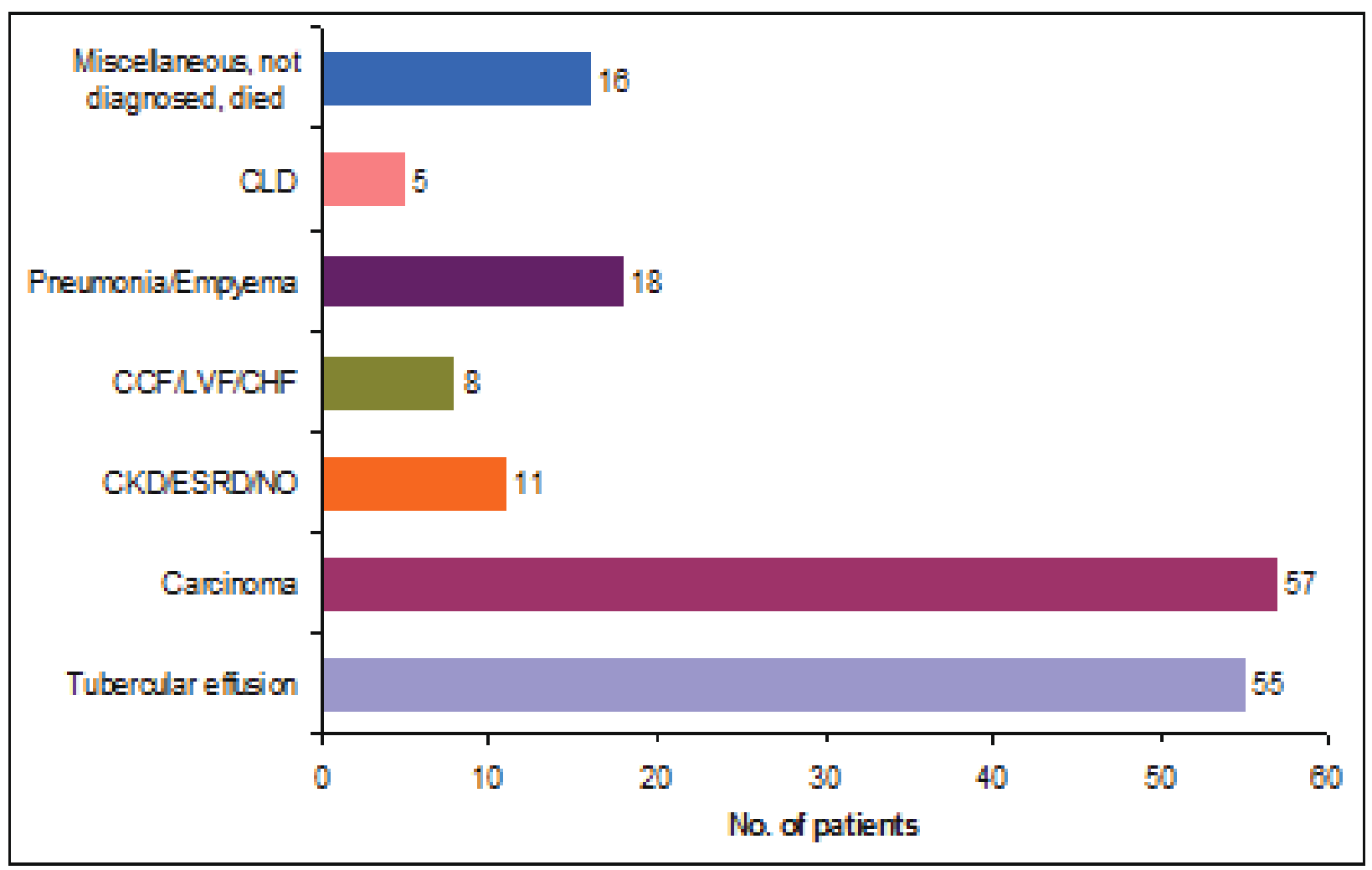

Fig-3: Bar diagram of different diseases

CLD: chronic liver disease; LVF: left ventricular failure; CHF: chronic heart failure; CKD: chronic kidney disease; ESRD: end stage renal disease; NS: nephrotic syndrome

Among the transudative pleural effusion chronic kidney disease/end stage renal disease, nephrotic syndrome were common (11 cases $6.47 \%$ ), followed by left ventricular and chronic heart failure ( 8 cases, $4.71 \%$ ). In this study the final diagnosis could be reached all but 6 cases. The distribution of the diagnosis is shown in the Figure-3. The most common diseases was malignancy followed by tubercular pleural effusion. The diagnosis which came out finally in this study revealed malignancy was the most common cause 57 (33.52\%). TPE was revealed in $55(32.35 \%)$ cases where as para pneumonic effusions were found in 18 (10.59\%) cases. Among the transudative pleural effusion chronic kidney disease/end stage renal disease, nephrotic syndrome were common (11 cases, 6.47\%), followed by left ventricular and chronic heart failure (8 cases, $4.71 \%$ ). In miscellaneous group, two patients were found in each rheumatoid arthritis and systemic lupus erythematosus, one patient of hypothyroidism, vasculitis and dengue fever. Two patient died and one patient left to other hospital. 


\section{Discussion}

Many markers that may be helpful in the differential diagnosis were studied in the pleural fluid. Two of these, ADA and interferon gamma are the most widely used and currently the most expected tests ${ }^{5}$. Especially ADA has been more commonly preferred for the diagnostics algorithms in the countries with a moderate to high incidence of tuberculosis because it is more inexpensive methods that can be accessed more quickly ${ }^{6}$.

This study showed malignancies were most common cause (57cases); Tubercular pleural effusion ranked second (55 cases) and para pneumonic effusion (18 cases) third most frequent cause. This differs from the study carried out at National Institute of diseases of chest and Hospital (NIDCH) by SK Bhoumik et al ${ }^{7}$ and NIDCH and Bangabandhu Sheikh Mujib Medical University (BSMMU) by Ahmed et al $^{8}$ where tubercular effusion was most common $(60.1 \% \mathrm{n}-106)$ and also from study in India'; where tubercular effusion was $66 \%(n-50)$. This is due to the fact that present study was conducted in a multi-disciplinary hospital where as other study of Bangladesh and India conducted at Chest diseases hospital and chest department respectively. More so as a tertiary care hospital all tubercular pleural effusion cases were not referred as dependent hospitals are equipped with TB and isolation ward. But this study result is similar to Turkey study ${ }^{10}$ where malignancies $(26 \%, n-240)$ was most common second to tubercular effusion (19\%, $\mathrm{n}-240$ ). Turkeys study showed that despite extensive investigations some causes of effusion remained unanswered in 6 cases. In this study, 6 cases remain undiagnosed in 6 cases. In the United States of America first three diseases in pleural effusion incidence were $\mathrm{CHF}$, parapneumonic effusion and malignant effusion ${ }^{11}$.

In this study the mean level of ADA was $37.31 \pm$ 33.21; in TPE ADA level was found in tubercular pleural fluid ranges from 25 to 180 with a mean $71.51 \pm 33.1$. It ranges $3 \mathrm{U} / \mathrm{L}$ to $170 \mathrm{U} / \mathrm{L}$ with nontubercular effusion with a mean $20.96 \pm 16.71$. It was found ADA level of the pleural fluid is significantly higher in TPE $(p<0.001)$ Similar type of result was found in other study conducted at Bangladesh ${ }^{7,8}$ and in India ${ }^{9}$ and Egypt ${ }^{12}$. Bhoumik SK et al studied pleural fluid ADA level along with histopathology of pleural biopsy in 103 cases at NIDCHand found a cut off ADA level of $40 \mathrm{U} / \mathrm{L}$ in pleural fluid which has sensitivity $94 \%$ and specificity $88 \%$. Sharmeen Ahmed et al also carried study at BSMMU and NIDCH among 50 patient with pleural biopsy/clinical trial among biopsy negative patient and found sensitivity $94 \%$ and specificity $88 \%$. They considered biopsy proven tubercular pleural effusion and biopsy negative but responded to ATT as tubercular case. The negative predictive value is $90 \%$ and positive predictive value is $92 \%$. Even comparison between tubercular and malignant pleural effusion by pleural fluid ADA activity also showed statistical significance $(p<0.0001)$.

In the Indian study by Mathur PC et al ${ }^{9}$ ADA is effective and cheap test with sensitivity $100 \%$ and specificity $94.6 \%$ with positive and negative predictive value of $95.5 \%$ and $100 \%$ respectively. Whereas in Egyptian study ${ }^{12}$ by revealed ADA positive (44 U/L) in number of cases 39 patients $(18 \%)$. Of these patients $24(62 \%)$ were diagnosed with TB, 9(23\%) with par pneumonic effusion, 2(5\%) with idiopathic effusion, 1 with malignant mesothelioma, 1 with lymphoma and one with rheumatoid pleurisy.

With a cut off value $40 \mathrm{U} / \mathrm{L}$ of pleural fluid ADA, ROC curve analysis showed high diagnostic sensitivity $89.47 \%$ andspecificity $95.58 \%$. Patients of nontubercular group showed $>40 \mathrm{U} / \mathrm{L}$ in 5 cases including 2 in malignancy, oneeach in parapneumonic effusion and in empyema and one in rheumatoid arthritis. Out of 55 TPE 6 patient had ADA value <40U/L. If ADA cut off value is considered $50 \mathrm{U} / \mathrm{L}$ then the sensitivity become $66.1 \%$ and specificity becomes $96.5 \%$ whereas ADA has the sensitivity and specificity $96.4 \%$ and $92.1 \%$ in case of cut off value $32 \mathrm{U} / \mathrm{L}$. In the following table comparison of the different studies regarding utility of pleural fluid is shown.

Table-VII: Utility of Pleural Fluid ADA in the diagnosis of tubercular pleural effusion

\begin{tabular}{|c|c|c|c|c|c|}
\hline Study & YEAR & $\begin{array}{l}\text { No of } \\
\text { Patients }\end{array}$ & $\begin{array}{c}\text { Threshold } \\
\text { U/L }\end{array}$ & $\begin{array}{c}\text { Sensitivity } \\
\%\end{array}$ & $\begin{array}{c}\text { Specificity } \\
\%\end{array}$ \\
\hline Bhoumik et al ${ }^{7}$ & 2008 & 62 & 40 & 94 & 88 \\
\hline Sharmeen et al ${ }^{8}$ & 2011 & 62 & 40 & 94 & 88 \\
\hline Valdes et al & 1993 & 405 & 47 & 100 & 95 \\
\hline Fatma Tokgoz ${ }^{10}$ et al & 2013 & 240 & 47 & 100 & 91 \\
\hline Helmy et a $\left.\right|^{12}$ & 2012 & 30 & 30 & 80 & 85 \\
\hline Mathur et al ${ }^{9}$ & 2006 & 50 & 100 & 100 & 100 \\
\hline Kabir et al & 2016 & 170 & 40 & 90.9 & 95.7 \\
\hline
\end{tabular}


The diagnosis which came out finally in this study revealed malignancy was the most common cause $57(33.52 \%)$. TPE was revealed in $55(32.35 \%)$ cases where as para pneumonic effusions were found in $18(10.59 \%)$ cases. Among the transudative pleural effusion chronic kidney disease/end stage renal disease, nephrotic syndrome are common (11 cases $6.47 \%$ ), followed by left ventricular and chronic heart failure (8 cases $4.71 \%$ ). In comparison the study at western India ( $n-50)$ by Bhavsar Kushal ${ }^{13}$ found TPE $66 \%$, Malignancy $18 \%$, parapneumonic $10 \%$, congestive cardiac failure $2 \%$ and hupoproteinemia $4 \%$.

\section{Conclusion}

This study revealed that ADA levels are significantly high in tubercular pleural effusion as against nontubercular causes. The method of ADA estimation is easy, simple and doesn't require expensive equipment. So, the study shown a simple, inexpensive, highly sensitive and specific test like ADA estimation should be employed to differentiate between tubercular and non-tubercular pleural effusion. So, finally this can be concluded that pleural fluid ADA is an useful surrogate marker for the diagnosis of tubercular pleural effusion.

\section{References}

1. WHO Global Tuberculosis report 2016.

2. Sharma SK and Mohan A. Extra pulmonary tuberculosis. Indian J Med Res 2004; 120:316-53.

3. Zaric B, Kuruc V, Milovancev A, et al. Differential diagnosis of tuberculous and malignant pleural effusion what is the role of adenosines deaminase? Lung 2008; 186:233-40.

4. Light RW. Tuberculous pleural effusionsin Pleural Disease. RW Light ed, William Wikins, Philadelphia; 2007:182-95.
5. Maskell NA, Butland RJ. Pleural Diseases Group Standards of care Committee. British Thoracic Society. BTS guidelines for the investigation of a unilateral pleural effusion in adults. Thorax 2003; 58(ii):8-17.

6. Krenke R, Korezynski P. Use of pleural Fluid levels of adenosine deaminase and interferon gamma in the diagnosis of tuberculous pleurities, Curr. Opin Pulm Med 2010; 16:367-75.

7. Bhoumik SK, Rahman MM, Ibrahim M, et al. Evaluation of adenosine deaminase activity for diagnosis of tuberculosis pleural effusion. Journal of pathology of Nepal 2013; 3:367-73.

8. Ahmed S, Fatema R, Saleh AA, et al. Diagnostic significance of pleural fluid adenosine deaminase activity in tuberculous pleurisy. Ibrahim Med Coll J 2011; 5(1):1-5.

9. Mathur PC, Tiwari KK, Tirkha S, et al. Diagnostic value of adenosine deaminase (ADA) activity in tubercular serositis. Indian J Tuberc 2005; 53:92-5.

10. Tokgoz F, Goksenouglu N, Bodur Y, et al. Retrospective Analysis of 240 Cases with Pleural Effusion. Eurasian J Pulmol 2014; 16:78-83.

11. Light RW. Clinical practice. Pleural Effusion. N Engl J Med 2002; 346:1971-7.

12. Helmy NA, Eissa SA, Masoud HH, et al. Diagnostic value of adenosine deaminase in tuberculosis and malignant pleural effusion. Egyptian Journal of Chest Diseases and Tuberculosis 2012; 61:413-7.

13. Kaushal MB, Krupal MP. Pleural effusion: A two year prospective study in western India. Sch J App Med Sci 2015; 3(8A):2790-3 . 